\title{
Sentinel node navigation segmentectomy for clinical stage IA non-small cell lung cancer
}


Koichi Kawanaka, MD, PhD, ${ }^{\mathrm{b}}$ Shinya Shiraishi, MD, PhD, ${ }^{\mathrm{b}}$ and Toshiaki Kobayashi, MD, $\mathrm{PhD}^{\mathrm{c}}$

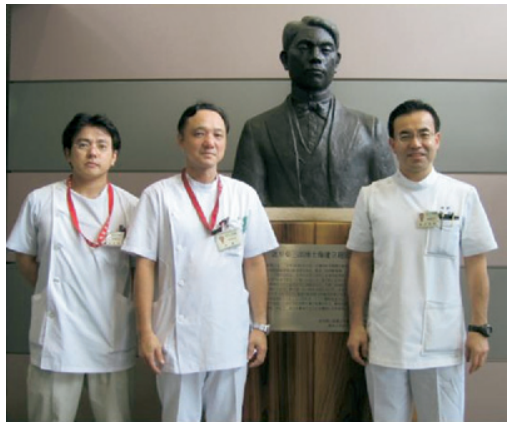

From right to left: Drs Nomori, Mori, and Ikeda The Bronze statue is Dr Shibasaburo Kitasato

From the Departments of Thoracic Surgery $^{\mathrm{a}}$ and Radiology, ${ }^{\mathrm{b}}$ Graduate School of Medical Sciences, Kumamoto University, Honjo, Kumamoto, Japan; and the Department of Assistive Diagnostic Technology, National Cancer Center Hospital, Tokyo, Japan.

This work was supported, in part, by Grantin-Aid from the Ministry of Health, Labor, and Welfare, Japan.

Received for publication Aug 20, 2006; revisions received Oct 7, 2006; accepted for publication Oct 23, 2006.

Address for reprints: Hiroaki Nomori, MD, $\mathrm{PhD}$, Department of Thoracic Surgery, Graduate School of Medical Sciences, Kumamoto University, 1-1-1 Honjo, Kumamoto 860-8556, Japan (E-mail: hnomori@ qk9.so-net.ne.jp).

J Thorac Cardiovasc Surg 2007;133:780-5

$0022-5223 / \$ 32.00$

Copyright (C) 2007 by The American Association for Thoracic Surgery

doi:10.1016/j.jtcvs.2006.10.027
Objective: Intraoperative frozen section examination of sentinel lymph nodes was conducted to determine the final indication for segmentectomy for clinical T1 N0 M0 non-small cell lung cancer.

Methods: Between April 2005 and July 2006, 52 patients with clinical T1 N0 M0 non-small cell lung cancer were prospectively treated by segmentectomy with sentinel node identification. The day before surgery, technetium- $99 \mathrm{~m}$ tin colloid was injected into the peritumoral region. After segmentectomy and lymph node dissection, sentinel nodes identified by measuring radioactive tracer uptake were examined for intraoperative frozen sections, which were serially cut 2 to $3 \mathrm{~mm}$ in thickness. When sentinel node metastasis was observed, segmentectomy was converted to lobectomy.

Results: Sentinel nodes were identified in $43(83 \%)$ patients. The average number of sentinel nodes was $1.6 \pm 0.9$ (range: $1-5$ ) per patient. Of 3 patients with metastatic sentinel lymph nodes, 2 underwent lobectomy and 1 larger segmentectomy. None of the other 40 patients had metastatic sentinel lymph nodes and therefore they were treated with segmentectomy. Pathologic staging with permanent sections was N0 in all of the 40 patients. On the other hand, in 9 patients whose sentinel nodes could not be identified, intraoperative frozen sections were required for $5.4 \pm 2.3 \mathrm{lymph}$ nodes, which was significantly more than $1.6 \pm 0.9$ in the 43 patients with sentinel node identification $(P<.001)$.

Conclusion: Sentinel node identification is useful to determine the final indication of segmentectomy for clinical T1 N0 M0 non-small cell lung cancer by targeting the lymph nodes needed for intraoperative frozen section diagnosis.

I n 1995, the Lung Cancer Study Group ${ }^{1}$ conducted a prospective randomized controlled trial of limited resection versus lobectomy for clinical T1 N0 M0 non-small cell lung cancer (NSCLC) and concluded that the former was inferior to the latter regarding local recurrence and survival. However, the limited resection group in the study included both segmentectomy and wedge resection, and the curability for T1 N0 M0 NSCLC differed between the two procedures. On the other hand, there have been several reports describing that survivals were similar between patients treated with segmentectomy and those with lobectomy. ${ }^{2-7}$

The most important issue regarding segmentectomy versus lobectomy is whether postoperative local recurrence is increased. Whereas Warren and $\mathrm{Faber}^{8}$ reported local recurrence in $15(22.7 \%)$ of 66 patients after segmentectomy versus $5(4.9 \%)$ of 103 patients after lobectomy, other authors reported that local recurrence after segmentectomy with complete dissection of hilar and mediastinal lymph nodes was equal to that after lobectomy. ${ }^{3-6}$ However, for determining the final indication for segmentectomy, intraoperative frozen sections must be examined for all of the hilar 


$$
\begin{aligned}
& \text { Abbreviations and Acronyms } \\
& \begin{aligned}
\mathrm{CT}= & \text { computed tomography } \\
\mathrm{FDG}-\mathrm{PET}= & \text { fluorodeoxyglucose-positron emission } \\
& \text { tomography } \\
\mathrm{NSCLC}= & \text { non-small cell lung cancer } \\
\mathrm{SN} & =\text { sentinel node } \\
\mathrm{SPECT}= & \text { single photon emission computed } \\
& \text { tomography }
\end{aligned}
\end{aligned}
$$

and lobe-specific mediastinal lymph nodes to confirm the intraoperative $\mathrm{N}$ staging to be $\mathrm{N0} .{ }^{3-6}$

A sentinel node ( $\mathrm{SN}$ ) is defined as the first lymph node within the lymphatic basin reached by lymph draining from the primary lesion. Recently, SNs have been identified by a radioactive tracer with or without dye during surgery for melanoma, breast cancer, gastrointestinal cancer, and lung cancer to reduce lymph node dissection. ${ }^{9-14} \mathrm{We}^{13,14}$ previously reported that SN identification with technetium-99m tin colloid could establish the first site of nodal metastasis in NSCLC.

In the present study, we used SN identification to target the lymph nodes submitted for intraoperative frozen section diagnosis, which might determine the indication of segmentectomy. In addition, unlike Tsubota, ${ }^{3}$ Okada, ${ }^{4}$ Yoshikawa, and their associates, who proposed that the indication for segmentectomy was T1 N0 M0 NSCLC less than $2 \mathrm{~cm}$ in size, we proposed that it was T1 N0 M0 NSCLC without size limitation. Because SN identification served as the final indication of segmentectomy, we named the procedure "sentinel node navigation segmentectomy."

\section{Patients and Methods \\ Eligibility}

The study protocol for SN navigation segmentectomy was approved by the Ethics Committee of Kumamoto University Hospital in March 2005. Informed consent was obtained from all patients after discussing the risks and benefits of the proposed surgery with their surgeons.

\section{Patients}

Between April 2005 and July 2006, 103 patients with NSCLC underwent surgical treatment. Of these, 73 patients had stage c-T1 N0 M0 cancer according to the findings of both computed tomography (CT) and fluorodeoxyglucose-positron emission tomography (FDG-PET). SN navigation segmentectomy was prospectively performed when (1) c-T1 N0 M0 NSCLC was identified in the peripheral lung; (2) the tumor on CT was more than $2 \mathrm{~cm}$ away from the pulmonary vein running at the boundary of the affected segment; (3) intraoperative frozen sections of SN showed no metastasis; (4) the surgical margin was intraoperatively found to be more than $2 \mathrm{~cm}$ from the tumor; and (5) tumors located centrally within the inner one third of the lung or in the right middle lobe were excluded. The stage of disease was based on the
TABLE 1. Lymph node nomenclature

\begin{tabular}{lc}
\hline N2 node & \multicolumn{1}{c}{ N1 node } \\
\hline Superior mediastinal & Hilar \\
No. 1. Highest mediastinal & No. 10. Hilar \\
No. 2. Paratracheal & No. 11. Interlobar \\
No. 3. Pretracheal & No. 12. Lobar \\
No. 4. Tracheobronchial & \\
Aortic & Intrapulmonary \\
No. 5. Botallo & No. 13. Segmental \\
No. 6. Para-aortic & No. 14. Subsegmental \\
Inferior mediastinal & \\
No. 7. Subcarinal & \\
No. 8. Paraesophageal & \\
No. 9. Pulmonary ligament & \\
\hline
\end{tabular}

TNM classification of the International Union Against Cancer. ${ }^{15}$ The lymph node nomenclature used was according to the lymph node map of Naruke and associates, ${ }^{16}$ which was approved by the Japan Lung Cancer Society (Table 1).

\section{Administration of Radioactive Colloid}

The day before surgery, a 23-gauge needle was introduced into the peritumoral region under single photon emission computed tomography/computed tomography (SPECT/CT) system guidance, which incorporates a gantry-free SPECT with dual-head detectors (Skylight; ADAC Laboratories, Milpitas, Calif) and an 8 multidetector CT scanner (Light-Speed Ultra; General Electrics, Milwaukee, Wis). Technetium tin colloid $(6-8 \mathrm{mCi})$ suspended in a 1 - to $1.5-\mathrm{mL}$ volume was injected in a single shot. SPECT/CT was performed 5 minutes after the injection and the next morning just before the operation.

\section{SN Identification}

The radioactivity of the resected lymph nodes was counted with a handheld gamma probe (Navigator; Auto Suture Japan, Tokyo, Japan). The radioactivity was measured for a 10 -second period. SN was defined as any node for which the count was more than 5 times the radioactivity of the resected tissue with the lowest count.

\section{SN Navigation Segmentectomy}

Under thoracotomy, SN navigation segmentectomy was performed as follows: (1) Pulmonary arteries and bronchi of the affected segments were cut at the hilum; (2) pulmonary veins along the boundary of segments were isolated from the center to periphery; (3) the affected segments along the pulmonary veins were resected with staplers; (4) the hilar and systematic mediastinal lymph nodes were dissected; (5) the radioactivity of dissected lymph nodes was counted for SN identification; (6) SNs were examined by intraoperative frozen sections, which were serially cut 2 to $3 \mathrm{~mm}$ in thickness; (7) if the intraoperative frozen sections of the SN showed no metastasis, the operation was completed with segmentectomy; (8) if the sections of the SN showed metastasis, lobectomy was performed; and (9) if the SN could not be identified because radioactivity of the lymph nodes was low, all of the hilar and lobe-specific mediastinal lymph nodes were submitted for 
TABLE 2. Sites of segmentectomy

\begin{tabular}{|c|c|c|c|}
\hline Segment & $\begin{array}{c}\text { No. of } \\
\text { patients }\end{array}$ & Segment & $\begin{array}{c}\text { No. of } \\
\text { patients }\end{array}$ \\
\hline Right & \multicolumn{2}{|c|}{ Left } & \\
\hline Upper lobe & \multicolumn{3}{|c|}{ Upper lobe } \\
\hline S1 & 3 & $S 1+2$ & 4 \\
\hline S2 & 2 & S3 & 2 \\
\hline $\mathrm{S} 1+\mathrm{S} 2$ & 2 & $\mathrm{~S} 1+2+3$ & 9 \\
\hline S3 & 2 & $S 4+5$ & 7 \\
\hline$S 3+S 2 b$ & 1 & & \\
\hline $\mathrm{S} 2+\mathrm{S} 3 \mathrm{a}$ & 1 & & \\
\hline Lower lobe & \multicolumn{3}{|c|}{ Lower lobe } \\
\hline S6 & 4 & S6 & 3 \\
\hline S7 +8 & 1 & S8 & 1 \\
\hline S8 & 1 & $S 8+9$ & 2 \\
\hline$S 9+S 10$ & 2 & $S 9+10$ & 1 \\
\hline$S 7-10$ & 1 & S10 & 1 \\
\hline $\mathrm{S} 6+\mathrm{S} 9+\mathrm{S} 10$ & 1 & S8-10 & 1 \\
\hline Total & 21 & & 31 \\
\hline
\end{tabular}

Right upper lobe: $S 1$, apical; $S 2$, anterior; $S 3$, posterior. Right lower lobe: $S 6$, apical; $S 7$, medial; $S 8$, anterior; $S 9$, lateral; $S 10$, posterior. Left upper lobe: $S 1+2$, apical posterior; $S 3$, apical anterior; $S 4$, superior lingular; $S 5_{\text {, }}$ inferior lingular. Left lower lobe: $S 6$, apical; $S 8$, anterior; $S 9$, lateral; $S 10$, posterior.

intraoperative frozen section. Lobe-specific lymph nodes were defined as follows: No. 3 and No. 4 for the right upper lobe, No. 5 for the left upper lobe, and No. 7 for the lower lobe of both sides. $^{17}$

\section{Primary End Points of the Study}

Primary end points of the study are as follows: (1) Can SN identification diagnose pathologic $\mathrm{N}$ stage during segmentectomy? (2) Are the survival and local recurrence after $\mathrm{SN}$ navigation segmentectomy similar to those after lobectomy?

\section{Statistical Analysis}

All data were analyzed for significance by the 2-tailed Student $t$ tests. All values in the text and tables are given as mean $\pm \mathrm{SD}$.

\section{Results}

Operative procedures for the 73 patients with c-T1 N0 M0 were lobectomy in 12 patients, segmentectomy in 52, and wedge resection in 9 . The reasons for conducting lobectomy in the 12 patients were as follows: (1) tumors in the right middle lobe in 5 patients; (2) tumors located centrally in 5 patients; (3) multiple lesions in the same lobe in 1 patient; and (4) thoracoscopic lobectomy as requested by the patient. As a result, 52 patients were consecutively enrolled for SN navigation segmentectomy. Table 2 shows the sites of segmentectomy for the 52 patients. The average number of dissected lymph node stations and lymph nodes per patient was $6 \pm 1.8$ stations and $12.5 \pm 5.9$ lymph nodes, respectively. Among the 52 patients, SNs could be identified in 43 (83\%). The time needed for SN identification was within 5
TABLE 3. Characteristics of patients with and without sentinel node identification

\begin{tabular}{lcc}
\hline & \multicolumn{2}{c}{ Sentinel lymph node } \\
\cline { 2 - 3 } & Identifiable & Nonidentifiable \\
\hline Mean age (y) & $69 \pm 7$ & $71 \pm 7$ \\
Sex & & \\
$\quad$ Male & 26 & 8 \\
$\quad$ Female & 17 & 1 \\
Mean tumor size (cm) & & $2.1 \pm 0.7$ \\
Histologic type & 37 & \\
Adenocarcinoma & 4 & 2 \\
Squamous cell carcinoma & 2 & 1 \\
Adenosquamous carcinoma & $1.6 \pm 0.9$ & $5.4 \pm 2.3^{*}$ \\
No. of lymph nodes submitted & & \\
$\quad$ for intraoperative frozen & & \\
diagnosis & & 9 \\
Pathologic TNM & 39 & 0 \\
T1 N0 M0 & 1 & 0 \\
T2 N0 M0 & 1 & 0 \\
T1 N1 M0 & 1 & 9 \\
T2 N1 M0 & 1 & \\
T1 N2 M0 & 43 & \\
Total & & \\
\hline
\end{tabular}

$* P<.001$.

minutes in each patient. The characteristics of the 43 patients with SN identification and of the 9 patients without are shown in Table 3. Average tumor size on CT was $1.9 \pm$ $0.7 \mathrm{~cm}$ (range: $0.8-3.0 \mathrm{~cm}$ ) and $2.1 \pm 0.7 \mathrm{~cm}$ (range: $1.4-3.0 \mathrm{~cm}$ ) in the patients with and without $\mathrm{SN}$ identification, respectively. Seventeen (40\%) of the 43 patients with SN identification and 4 (44\%) of 9 patients without had tumors larger than $2 \mathrm{~cm}$. Pathologic tumor stages in the 43 patients with SN identification were T1 N0 M0 in 39, T2 N0 $\mathrm{M} 0$ in 1, T1 N1 M0 in 1, T2 N1 M0 in 1, and T1 N2 M0 in 1 , whereas the stage in all 9 patients without $\mathrm{SN}$ identification was p-T1 N0 M0. The tumors in 2 patients were pathologically classified as $\mathrm{T} 2$; one tumor was spread over the pleura and the other was more than $3 \mathrm{~cm}$ in size in the permanent section. The average number of lymph nodes submitted for intraoperative frozen section examination was significantly less in the 43 patients with $\mathrm{SN}$ identification (1.6 \pm 0.9 [range: $1-5$ ] per patient) than in the 9 patients without SN identification (5.4 \pm 2.3 [range: $3-10$ ] per patient) $(P<.001)$.

Table 4 shows the $\mathrm{SN}$ identified in the hilar lymph node stations. The number of stations having $\mathrm{SN}$ increased in numeric order from No. 10 to 13 stations. In the mediastinal lymph node stations, the SN was identified in 15 of the 43 patients (35\%). Eleven of the 15 patients had SNs in both the hilar and mediastinal lymph node stations, whereas the remaining 4 patients had SNs only in the mediastinum. The distribution of mediastinal SNs is shown in Table 5, which 
TABLE 4. Sentinel lymph node mapping in the hilar lymph node stations

\begin{tabular}{ccc}
\hline & \multicolumn{2}{c}{ Sentinel nodes } \\
\cline { 2 - 3 } Station & No. of patients & Percent \\
\hline 10 & $7 / 3$ & 16.3 \\
11 & $7 / 43$ & 16.3 \\
12 & $12 / 43$ & 27.9 \\
13 & $22 / 43$ & 51.2 \\
\hline
\end{tabular}

was lobe-specific; that is, 3 of the 10 patients with primary tumor in the right upper lobe had SN in No. 3 or 4 stations; 3 of the 9 patients with primary tumor in the right lower lobe had SN in No. 7, 3, or 4 stations; 8 of the 18 patients with primary tumor in the left upper lobe had SN in No. 5 station; and 2 of the 6 patients with primary tumor in the left lower lobe had SN in No. 7 station.

In $3(7 \%)$ of the 43 patients with $\mathrm{SN}$ identification, metastasis was found in the $\mathrm{SN}$ by intraoperative frozen section (Table 6). For 2 of the 3 patients (patients 1 and 2), operative procedures were converted to lobectomy. The operative procedure for the remaining patient (patient 3) was converted from posterior apical segmentectomy to larger segmentectomy (upper division segmentectomy, but not to upper lobectomy), because of his age ( 80 years old). Pathologic N stages were N1 in 2 patients and N2 in 1 patient. Although both patients 1 and 2 had metastasis only in the SN, patient 3 had metastasis in both SN (No. 5) and non-SN (Nos. 12 and 13). Tumors in all of the other 40 patients were classified as p-N0 by permanent sections.

There were no complications associated with radioisotope injection necessitating tube drainage, such as bleeding or severe pneumothorax. One patient had empyema 3 days after segmentectomy, which was cured by drainage and antibiotics on the $23 \mathrm{rd}$ postoperative day. There were no the other major complications associated with segmentectomy, including prolonged air leakage of more than 5 days. The postoperative follow-up was performed by chest and abdominal CT and brain magnetic resonance imaging every 3 months after the operation. No patients were lost to followup. The mean follow-up period after surgery in the 52 patients was 8 months (range: 1-15 months). Postoperative recurrence occurred in 1 patient, who underwent an apical segmentectomy of the right lower lobe for adenosquamous carcinoma $2.9 \mathrm{~cm}$ in size. The recurrence was at 5 months after segmentectomy, at the extraregional lymph node for tumor in the right lower lobe, that is, at the interlobar lymph node (No. 11) between the right upper lobe and middle lobe, and treated by completion pneumonectomy. During the segmentectomy of this patient, No. 13 and No. 4 were identified as SNs, which showed no metastasis in intraoperative frozen sections. The patient is now alive 11 months
TABLE 5. Sentinel nodes at the mediastinum in each lobe

\begin{tabular}{lccc}
\hline Tumor location & Station of mediastinal SN & No. of patients & Percent \\
\hline RUL & 3 or 4 & $3 / 10$ & 30.0 \\
RLL & 3 or 4 & $2 / 9$ & 22.2 \\
& 7 and 3 & $1 / 9$ & 11.2 \\
LUL & 5 & $8 / 18$ & 44.4 \\
LLL & 7 & $2 / 6$ & 33.3 \\
\hline
\end{tabular}

$S N$, Sentinel node; $R U L$, right upper lobe; $R L L$, right lower lobe; $L U L$, left upper lobe; LLL, left lower lobe.

after the completion pneumonectomy without recurrence. The other 51 patients are also now alive without recurrence.

\section{Discussion}

The present study shows that the SN navigation segmentectomy using radioisotope tracers could increase the accuracy of intraoperative $\mathrm{N}$ staging and could serve as the final indication for segmentectomy. In the 3 patients with $\mathrm{N} 1$ or N2 disease, intraoperative frozen sections of SNs showed metastasis, which suggested the need for lobectomy. In 9 segmentectomy-treated patients whose SNs could not be identified, all hilar and lobe-specific lymph nodes were required for diagnosis, a significantly larger number than in the 43 patients whose SNs could be identified. SN identification therefore could determine a final indication for segmentectomy by targeting the lymph nodes needed for intraoperative frozen section diagnosis. In addition, serial sections of SNs during surgery might find micrometastasis more easily than single section in each of a larger number of lymph nodes.

Although the postoperative follow-up period is still short, 1 patient had local recurrence 5 months after segmentectomy. The recurrence site of this patient, however, was the extraregional lymph node. In addition, the histologic type of this patient was adenosquamous carcinoma, which is known to have poorer prognosis than other types of NSCLC. ${ }^{18,19}$ We therefore consider that the patients with clinical T1 N0 M0 NSCLC of high malignant grade, such as adenosquamous carcinoma, large cell neuroendocrine carcinoma, adenocarcinoma with high FDG uptake on PET, and NSCLC with high carcinoembryonic antigen serum level, would be preferably treated by lobectomy rather than segmentectomy, even if the intraoperative lymph node staging is $\mathrm{N} 0$.

Skip metastasis to the mediastinal lymph nodes has been reported to occur in $20 \%$ to $40 \%$ of patients with NSCLC, ${ }^{17,20}$ which could be because some lymphatic flow from the lung goes directly to the mediastinum through the pleura and not to the hilar lymph node stations. ${ }^{21}$ The present study showed that SNs were identified in the mediastinum in 15 (35\%) of 43 patients and the lymphatic route to each mediastinal lymph node station was lobe-specific. 
TABLE 6. Patients who were converted to major lung resection

\begin{tabular}{ccccccc}
\hline Patient No. & Age/sex & $\begin{array}{c}\text { Histologic } \\
\text { type }\end{array}$ & Planned segmentectomy & $\begin{array}{c}\text { SN with } \\
\text { metastasis }\end{array}$ & $\begin{array}{c}\text { Converted } \\
\text { procedure }\end{array}$ & Pathologic TNM \\
\hline 1 & $70 / \mathrm{M}$ & $\mathrm{Ad}$ & Apical segment of RLL & No. 13 & Lobectomy \\
2 & $72 / \mathrm{M}$ & $\mathrm{Ad}$ & Apical segment of RLL & No. 11 & Lobectomy & T1 N1 M0 \\
3 & $80 / \mathrm{M}$ & $\mathrm{Ad}$ & Posterior apical segment of LUL & No. 5 & Upper division \\
& & & & & T1 N2 M0 \\
& & & & &
\end{tabular}

$S N$, Sentinel node; $A d$, adenocarcinoma; $R L L$, right lower lobe; $L U L$, left upper lobe.

Therefore, to determine the intraoperative indication for segmentectomy without using SN identification, not only hilar lymph nodes but also lobe-specific mediastinal lymph nodes should be submitted for intraoperative frozen section diagnosis. The SN identification can target the lymph nodes among those.

The identification rate of SNs was $83 \%$ in the present study, as it was in the data of previous reports by several authors, that is, $63 \%$ to $82 \% .{ }^{12-14} \mathrm{We}^{14}$ previously reported the results of SN identification in 104 patients with clinical stage I NSCLC. Of the 104 patients, 15 patients had N1 or $\mathrm{N} 2$ disease. Although SN could be found to have metastases during the operation in $13(87 \%)$ of those 15 patients, it produced false negative results in the remaining 2 patients. One of the 2 patients had T2 tumor and metastasis in the No. 12 nodal station, and the other had T1 tumor and metastasis in the No. 14 nodal station, which could not be identified as $\mathrm{SN}$ by our procedure because of its intrapulmonary location. We therefore believe that $\mathrm{SN}$ could be identified by our procedure in most of the patients with T1 N0 M0 NSCLC.

Although it has been reported that $20 \%$ to $25 \%$ of patients with clinical stage I disease have mediastinal lymph node metastasis, ${ }^{22,23}$ the present study showed only $3(6 \%)$ of 52 patients with $\mathrm{N} 1$ or $\mathrm{N} 2$ disease. Our procedure for lymph node dissection was systematic and then yielded $6 \pm$ 1.8 nodal stations and $12.5 \pm 6$ lymph nodes to be dissected per patient. The low number of patients with $\mathrm{N} 1$ or N2 disease in the present study is probably due to the institutional setting; that is, most lung cancers in our patients were found by routine $\mathrm{CT}$ examination, resulting in a higher rate of early-stage NSCLC than usual.

The Lung Cancer Study Group study in 1995 (the only prospective randomized trial of lobectomy versus limited resection for T1 N0 NSCLC) reported that limited resection was inferior to lobectomy regarding death rate and local recurrence. ${ }^{1}$ However, the study included a significant number $(33 \%)$ of wedge resections in the limited resection group and did not analyze the results of segmentectomy. In addition, compared with clinical staging in 1995 when the Lung Cancer Study Group study was reported, it is now more accurate because of improved CT and FDG-PET technology. Therefore, a prospective randomized trial of lobectomy versus segmentectomy should be performed for c-T1 N0
M0 NSCLC. The SN navigation segmentectomy, which can target lymph nodes for intraoperative frozen section diagnosis, is a reasonable procedure for determining the final indication of segmentectomy.

\section{References}

1. Lung Cancer Study Group, Ginsberg RH, Rubinstein LV. Randomized trial of lobectomy versus limited resection for T1N0 non-small cell lung cancer. Ann Thorac Surg. 1995;60:615-23.

2. Jensik RJ, Faber LP, Milloy FJ, Monson DO. Segmental resection for lung carcinoma. J Thorac Cardiovasc Surg. 1973;66:563-72.

3. Tsubota N, Ayabe K, Doi O, Mori T, Namikawa S, Taki T, et al. Ongoing prospective study of segmentectomy for small lung tumors. Ann Thorac Surg. 1998;66:1787-90.

4. Okada M, Yoshikawa K, Hatta T, Tsubota N. Is segmentectomy with lymph node assessment an alternative to lobectomy for non-small cell lung cancer of $2 \mathrm{~cm}$ or smaller? Ann Thorac Surg. 2001;71:956-61.

5. Yoshikawa K, Tsubota N, Kodama K, Ayabe H, Taki T, Mori T. Prospective study of extended segmentectomy for small lung tumors: the final report. Ann Thorac Surg. 2002;73:1055-9.

6. Kodama K, Doi O, Higashiyama M, Yokouchi H. Intentional limited resection for selected patients with T1 N0 M0 non-small cell lung cancer. J Thorac Cardiovasc Surg. 1997;114:347-53.

7. Harada H, Okada M, Sakamoto T, Matsuoka H, Tsubota N. Functional advantage after radical segmentectomy versus lobectomy for lung cancer. Ann Thorac Surg. 2005;80:2041-5.

8. Warren WH, Faber LP. Segmentectomy versus lobectomy in patients with stage I pulmonary carcinoma: five-year survival and patterns of intrathoracic recurrence. J Thorac Cardiovasc Surg. 1994;107:1087-93.

9. Tafra L, Lannin DR, Swanson MS, Eyk JJV, Verbanac KM, Chua AN, et al. Multicenter trial of sentinel node biopsy for breast cancer using both technetium sulfur colloid and isosulfan blue dye. Ann Surg. 2001;233:51-9.

10. Morton DL, Thompson JF, Essner R, Elashoff R, Stern SL, Nieweg $\mathrm{OE}$, et al. Validation of the accuracy of intraoperative lymphatic mapping and sentinel lymphadenectomy for early-stage melanoma. Ann Surg. 1999;230:453-65.

11. Kitagawa Y, Fujii H, Mukai M, Kubota T, Ando N, Watanage M, et al. The role of the sentinel lymph node in gastrointestinal cancer. Surg Clin North Am. 2000;80:1799-809.

12. Liptay MJ, Masters GA, Winchester DJ, Edelman BL, Carrido BJ, Hirshctritt TR, et al. Intraoperative radioisotope sentinel lymph node mapping in non-small cell lung cancer. Ann Thorac Surg. 2000;70:384-90.

13. Nomori H, Horio H, Naruke T, Orikasa H, Yamazaki K, Suemasu K. Use of technetium-99m tin colloid for sentinel lymph node identification in non-small cell lung cancer. J Thorac Cardiovasc Surg. 2002; 124:486-92.

14. Nomori H, Watanabe K, Ohtsuka T, Naruke T, Suemasu K. In vivo identification of sentinel lymph nodes for clinical stage I non-smal cell lung cancer for abbreviation of mediastinal lymph node dissection. Lung Cancer. 2004;46:49-55.

15. Sobin LH, Wittekind CH, editors. UICC: TNM classification of malignant tumors. 6th ed. New York: John Wiley \& Sons; 2002. 
16. Naruke T, Suemasu K, Ishikawa S. Lymph node mapping and curability at various levels of metastasis in resected lung cancer. $J$ Thorac Cardiovasc Surg. 1978;76:832-9.

17. Naruke T, Tsuchiya R, Kondo H, Nakayama H, Asamura H. Lymph node sampling in lung cancer: how should it be done? Eur J Cardiothorac Surg. 1999;16:S17-24.

18. Shimizu J, Oda M, Hayashi Y, Nonomura A, Watanabe Y. A clinicopathologic study of resected cases of adenosquamous carcinoma of the lung. Chest. 1996;109:9889-94.

19. Nakagawa K, Yasumitsu T, Fukuhara K, Shiono H, Kikui M. Poor prognosis after lung resection for patients with adenosquamous carcinoma of the lung. Ann Thorac Surg. 2003;75:1740-4.
20. Okada M, Tsubota N, Yoshimura M, Miyamoto Y, Matsuoka H. Prognosis of completely resected $\mathrm{pN} 2$ non-small cell lung carcinomas: what is the significant node that affects survival? J Thorac Cardiovasc Surg. 1999;118:270-5.

21. Riquet M, Hidden G, Debesse B. Direct lymphatic drainage of lung segments to the mediastinal nodes. J Thorac Cardiovasc Surg. 1989;97:623-32.

22. Seely JM, Mayo JR, Miller RR, Muller NL. T1 lung cancer: prevalence of mediastinal node metastases and diagnostic accuracy of CT. Radiology. 1993;186:129-32.

23. Heavey LR, Glazer GM, Gross BH, Francis IR, Orringer MB. The role of CT in staging radiographic T1N0M0 bronchogenic cancer. AJR. 1986;146:285-90. 